Thomas Geissmann · Thomas Mutschler

\title{
Diurnal distribution of loud calls in sympatric wild indris (Indri indri) and ruffed lemurs (Varecia variegata): implications for call functions
}

Received: 16 March 2005/ Accepted: 9 December 2005/Published online: 31 May 2006

(c) Japan Monkey Centre and Springer-Verlag 2006

\begin{abstract}
We carried out a short study on the diurnal call distribution of two sympatric lemurs in the Réserve Naturelle Intégrale Zahamena (eastern Madagascar). Whereas indris (Indri) song bouts were clearly concentrated in the early morning hours, the roar/shriek choruses of ruffed lemurs (Varecia) exhibited a much more even distribution throughout the day. These differences in distribution pattern support earlier claims that indri song bouts are more likely to serve territorial functions, whereas ruffed lemur loud calls may serve both spacing and/or alarm call functions.
\end{abstract}

Keywords Calls $\cdot$ Diurnal distribution . Function of calls $\cdot$ Song $\cdot$ Madagascar

\section{Introduction}

The loud calls of ruffed lemurs (Varecia) and indris (Indri) are among the most impressive calls known from the malagasy primates. Ruffed lemurs are known to produce loud roar/shriek choruses (Pereira et al. 1988). These choruses consist of several call types and exhibit a duration of several seconds. The calls are contagious, and most or all group members participate in the choruses (Pereira et al. 1988; Petter 1962). During choruses, ruffed lemurs take a characteristic quadrupedal body posture with lowered head and tail and proclined shoulders (Pereira et al. 1988). Often, choruses appear to start with no discernible external stimulus. Ruffed lemur choruses have been reported to be particularly common in the morning and evening hours (Macedonia and Taylor 1985; Pereira et al. 1988; Petter and CharlesDominique 1979; Petter et al. 1977). Several functions

T. Geissmann $(\bowtie) \cdot$ T. Mutschler

Anthropological Institute, University Zürich-Irchel,

Winterthurerstrasse 190, 8057 Zürich, Switzerland

E-mail: thomas.geissmann@aim.unizh.ch

Tel.: + 41-44-6355411

Fax: + 41-44-6356804 have been proposed for the roar/shriek choruses of ruffed lemurs: (1) a spacing function between groups (Pereira et al. 1988; Rigamonti 1993), (2) an alarm function against predators, particularly birds of prey (Kress et al. 1978; Macedonia and Taylor 1985; Petter and Charles-Dominique 1979; Pereira et al. 1988), (3) to establish or defend territories (White 1991; Rigamonti 1993), and (4) for coordination of movement within the territory (White 1991).

The long and loud vocalizations of indris have repeatedly been termed 'songs' (Haimoff 1986; Oliver and O'Connor 1980; Pollock 1975, 1986; Thalmann et al. 1993). Various sequences can be differentiated within a song. The most prominent of them is the descending phrase sequence which appears to consist typically of a relatively tightly-coordinated pattern of vocal interaction (duet) between group members (Thalmann et al. 1993). Previous studies appear to agree that the main functions of indri songs are related to territorial announcement and defense (Petter and CharlesDominique 1979; Petter et al. 1977; Pollock 1986).

Very little data in support of these different functions of indri songs and ruffed lemurs choruses have been published, and the functions must be regarded as tentative approximations. Furthermore, although adult group members of either sex participate in indri songs and ruffed lemur choruses, the proposed functions of these calls need not necessarily be identical for both sexes. However, this was not further examined in our study. If the proposed functions of the calls are correct for at least one sex class, the diurnal call distribution should be influenced by distinct selective pressures, which allows us to make testable predictions.

Holders of established and stable territories are probably familiar with their neighbors. In order to defend their territory vocally, they are likely to confine their calling activity to a relatively short time interval when information transfer is optimal (Brown and Handford 2003; Green and Marler 1979; Waser and Brown 1984, 1986). Many bird songs and gibbon songs exhibit a distinct calling peak in the early morning hours 
(Brown and Handford 2003; Dabelsteen and Mathevon 2002; Geissmann 2000, 2002). Calling during this interval may be sufficient to inform neighbors of the continued presence of the territory holders.

In contrast, the production of alarm calls is influenced by the occurrence of alarming stimuli, and a consistent concentration of these stimuli to a narrow time interval would be less obvious. Likewise, spacing calls or intra-group coordinating calls may require an occasional repetition during the activity period, because neighbors cannot predict each other's paths after a single round of calls, and a group may need to coordinate group members more than once. In summary, if the proposed functions of the examined calls are correct, indri songs are more likely to be concentrated to a relatively narrow time window. Ruffed lemur choruses, on the other hand, should be more evenly distributed throughout the callers' activity period for the proposed functions (1), (2) and (4), but exhibit a similar distribution to indri song bouts if the proposed function (3) is the main one. The present study aims to test these predictions.

\section{Methods}

We carried out a short study on the distribution of lemur loud calls in the western part of the Réserve Naturelle Intégrale de Zahamena. This reserve is situated in the in the eastern escarpments of Madagascar. It is located approximately $50 \mathrm{~km}$ inland and covers an area of about $640 \mathrm{~km}^{2}$. Altitudes range from 200 to $1,500 \mathrm{~m}$ above sea level. Humidity is generally high throughout the year (1,500-2,000 $\mathrm{mm}$ rain annually), though lessening to the west, and temperatures are moderate (monthly means ranging from 15 to $24^{\circ} \mathrm{C}$ ). The vegetation consists of rainforest in the east, changing to humid forest to semi-humid forest in the western parts of the protected areas. The core protected areas consist of two national park lots and one parcel of strict nature reserve that are surrounded by buffer zones where controlled extraction of some forest products takes place. Outside the protected areas and buffer zones primary forest is virtually non-existent in the area (Byg and Balslev 2001). Twelve lemur species have been reported from Zahamena (Ganzhorn 1998; Mittermeier et al. 1994).

Data were collected during 4 days (21-24 August $1998)$ in the area around Camp $1\left(17^{\circ} 39.7^{\prime} \mathrm{S}, 48^{\circ} 39.4^{\prime} \mathrm{E}\right)$, and during 4 days (25-28 August 1998) in the area around Camp $2\left(17^{\circ} 39.9^{\prime} \mathrm{S}, 48^{\circ} 40.1^{\prime} \mathrm{E}\right)$, about $1.3 \mathrm{~km} \mathrm{SE}$ of Camp 1. Survey walks in various directions were carried out daily from 0600 to 1200 hours; additional surveys were carried out at varying times during the afternoons, evenings and nights.

A total of $58 \mathrm{~h}$ were spent on survey walks. Survey hours were not evenly distributed across all hours of the day and night. In order to avoid bias, we calculated the calling rate for each 30-min time block separately. Because we would not have been able to hear calls during the background noise of heavy rain, these periods were excluded from the calculation. Each 30-min block from 0600 to 1200 hours was completely surveyed 5.7 times on average (standard deviation 0.5, range 4.5-6), and each 30-min block from 1200 to 1800 hours was completely surveyed 3.5 times on average (standard deviation 1.4, range 1-5)

During surveys, we recorded starting time, ending time, estimated distance and direction of all indri song bouts and ruffed lemur choruses. Two other, less prominent types of loud indri vocalizations (i.e. wa notes and honk notes, sensu Thalmann et al. 1993) are not included in this study. Calls of the same individual or group had to be separated by an arbitrarily defined duration of at least $5 \mathrm{~min}$ in order to be counted as two events.

Direct encounters with lemurs occurred with the following species: brown lemur (Eulemur fulvus) $(n=2$ encounters), red-bellied lemur (Eulemur rubriventer) $(n=1)$, black-and-white ruffed lemur (Varecia variegata) $(n=2)$, indri (Indri indri) $(n=3)$, diademed sifaka (Propithecus diadema) $(n=4)$ during day surveys, and eastern woolly lemur (Avahi laniger) $(n=1)$, red mouse lemur (Microcebus rufus) $(n=2)$, fork-crowned lemur (Phaner sp.) $(n=1)$ during night surveys.

\section{Results}

Both study species appeared to exhibit a diurnal calling pattern, because no calls were heard during night surveys (i.e. the time between 1800 and 0600 hours). During the day $(0600-1800$ hours), indri song bouts $(n=159)$ were heard significantly more often than choruses of ruffed lemurs $(n=49)$ (Chi-square goodness-of-fit test with two cells, $d f=1, P<0.001)$. The difference is also significant if the number of indri and ruffed lemur calls of each 0.5 -h segment of the day are compared in a twosamples test for paired data (Wilcoxon signed-rank test, $n=25, P=0.018$ ).

The calling frequency is not significantly correlated between the two species (Spearman rank correlation, Rho $=-0.03, n=25, P>0.05)$. Indri song bouts are not randomly distributed across the day, but are preferentially uttered in the early morning hours. A clear peak in vocal activity occurs in the time from 0800 to 0930 hours, when more than $37 \%$ of all songs occur (Fig. 1a). In contrast, ruffed lemur calls do not exhibit a clear calling peak (Fig. 1b). As a result, the higher number of indri song bouts versus ruffed lemur choruses is even more significantly higher (Wilcoxon signed-rank test, $n=14, P=0.002$ ), if only the morning data are considered (i.e. the 0.5-h segments before 1300 hours). In the afternoon, the proportion reverses and indri song bouts occur significantly less often than ruffed lemur choruses $(n=11, P=0.048)$. 

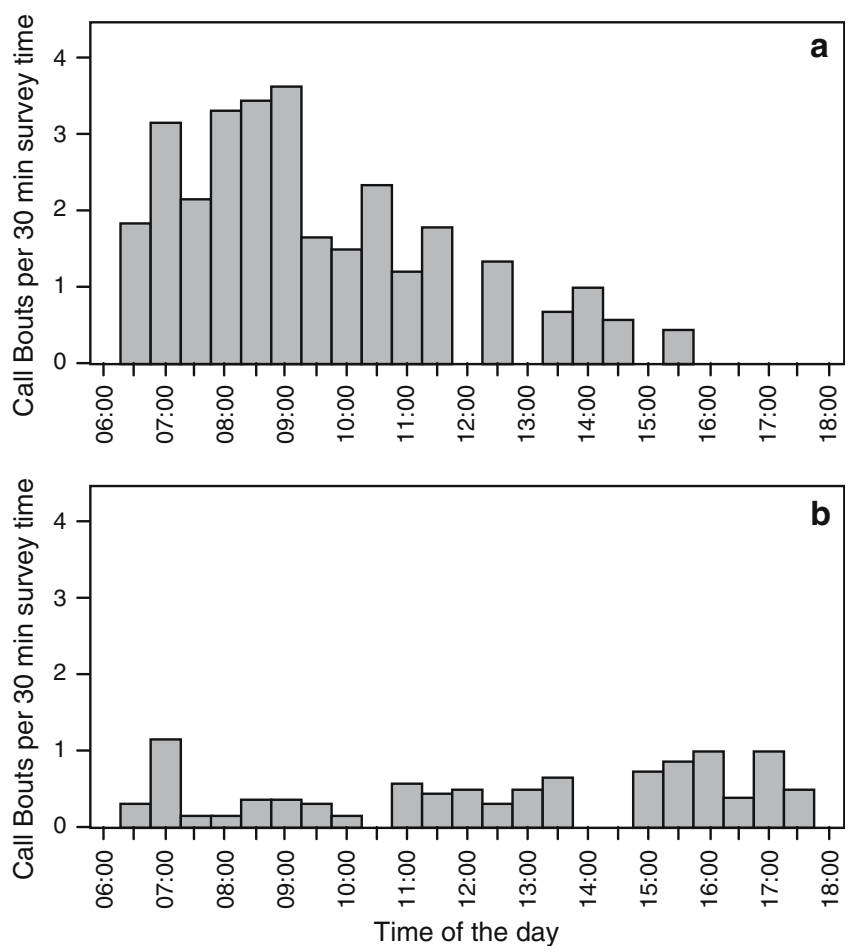

Fig. 1 Average frequency of indri (Indri indri) song bouts (a) and ruffed lemur (Varecia variegata) calls (b) per 0.5-h survey time

\section{Discussion}

We found a pronounced difference between the diurnal distribution pattern of indri songs and the roar/shriek choruses of ruffed lemurs. Whereas the former are concentrated to a relatively narrow time window during the morning, ruffed lemur choruses are more evenly distributed throughout the day. This findings provide first indirect support to the previously proposed call functions, according to which indri songs serve territorial announcement and defense, whereas choruses of ruffed lemurs serve either inter-group spacing, alarm, or intragroup coordination. However, a territorial function for ruffed lemurs choruses, as proposed by White (1991) and Rigamonti (1993), appears less likely.

Our study does not represent proof for any of the proposed functions. By testing hypotheses derived from the proposed functions, we provide support for some of the functions which, albeit indirectly, is also independent of the reports which proposed the functions in the first place.

Our results should be regarded with some caution because they are based on a short study. The calling distribution of indris has been reported to exhibit seasonal fluctuations (Pollock 1986). Nocturnal indri songs and ruffed lemur choruses have been mentioned in previous reports (Petter 1962; Petter and Charles-Dominique 1979; Petter et al. 1977), although no quantitative data on these observations were presented. It should be noted, however, that our frequency distribution of indri song bouts (Fig. 1) is virtually identical to the one presented by Pollock (1986, his Fig. 5) based on a much longer study of indris at two more southern localities. Likewise, a short study on captive red ruffed lemurs (Varecia variegata rubra) (Traber 2004) presented quantitative data on diurnal call distribution which revealed no clear calling peaks, thus also providing at least some support for our finding.

Acknowledgments We thank the Direction des Eaux et Forêts for permission to conduct research in the Réserve Naturelle Intégrale Zahamena and Mamirina Rakotorahalany Josoa, Rajaonarivo Aimé Bernard and M. Ratodymanana for assistance in the field. Two anonymous reviewers kindly read and commented on our manuscript. T.G. was supported by a grant from the Deutsche Forschungsgemeinschaft.

\section{References}

Brown TJ, Handford P (2003) Why birds sing at dawn: the role of consistent song transmission. Ibis 145:120-129

Byg A, Balslev H (2001) Diversity and use of palms in Zahamena, eastern Madagascar. Biodiv Conserv 10:951-970

Dabelsteen T, Mathevon N (2002) Why do songbirds sing intensively at dawn? A test of the acoustic transmission hypothesis. Acta Ethol 4:65-72

Ganzhorn JU (1998) Nested patterns of species composition and their implications for lemur biogeography in Madagascar. Folia Primatol 69(Suppl 1):332-341

Geissmann T (2000) Gibbon songs and human music from an evolutionary perspective. In: Wallin NL, Merker B, Brown S (eds) The origins of music. MIT Press, Cambridge, pp 103123

Geissmann T (2002) Duet-splitting and the evolution of gibbon songs. Biol Rev 77:57-76

Green S, Marler P (1979) The analysis of animal communication. In: Marler P, Vandenberg J (eds) Handbook of behavioral neurobiology, vol 3. Plenum Press, New York, pp 73-158

Haimoff EH (1986) Convergence in the duetting of monogamous old World monkeys. J Hum Evol 15:51-59

Kress JH, Conley JM, Eaglen RH, Ibanez AE (1978) The behaviour of Lemur variegatus Kerr 1792. Z Tierpsychol 48:87-99

Macedonia JM, Taylor LL (1985) Subspecific divergence in a loud call of the ruffed lemur (Varecia variegata). Am J Primatol 9:295-304

Mittermeier RA, Tattersall I, Konstant WR, Meyers DM, Mast RB (1994) Lemurs of Madagascar. Conservation International, Washington, DC

Oliver WLR, O'Connor SM (1980) Circadian distribution of Indri indri group vocalisations: a short period sampling at two study sites near Perinet, eastern Madagascar. Dodo J Jersey Wildl Preserv Trust 17:19-27

Pereira ME, Seeligson ML, Macedonia JM (1988) The behavioral repertoire of the black-and-white ruffed lemur, Varecia variegata variegata (Primates: Lemuridae). Folia Primatol 51:1-32

Petter J-J (1962) Recherches sur l'écologie et l'éthologie des Lémuriens Malgaches. Mém Mus Natl Hist Nat, Sér A, Zool 27 (1): $1-146,+26$ plates

Petter J-J, Albignac R, Rumpler Y (1977) Faune de Madagascar vol 44: Mammifères Lémuriens (Primates Prosimiens). ORSTOM/CNRS, Paris

Petter J-J, Charles-Dominique P (1979) Vocal comunication in prosimians. In: Doyle GA, Martin RD (eds) The study of prosimian behavior. Academic, New York, pp 247-305

Pollock JI (1975) Field observations on Indri indri: a preliminary report. In: Tattersall I, Sussman RW (eds) Lemur biology. Plenum Press, New York, pp 287-311 
Pollock JI (1986) The song of the indris (Indri indri; Primates: Lemuroidea): natural history, form, and function. Int $\mathbf{J}$ Primatol 7:225-267

Rigamonti MM (1993) Home range and diet in red ruffed lemurs (Varecia variegata rubra) on the Masoala peninsula, Madagascar. In: Kappeler PM, Ganzhorn JU (eds) Lemur social systems and their ecological basis. Plenum Press, New York, London, pp 25-39

Thalmann U, Geissmann T, Simona A, Mutschler T (1993) The indris of Anjanaharibe-Sud, northeastern Madagascar. Int $\mathbf{J}$ Primatol 14:357-381

Traber SY (2004) Raumnutzung und Aktivität bei Roten Varis (Varecia variegata rubra) und Weisskopfmakis (Eulemur fulvus albifrons) im Kleinaffenhaus und der Masoala-Halle des Zoo Zürich. Diploma Thesis, Anthropological Institute, Zürich University, pp 49

Waser PM, Brown CH (1984) Is there a "sound window" for primate communication? Behav Ecol Sociobiol 15:73-76

Waser PM, Brown CH (1986) Habitat acoustics and primate communication. Am J Primatol 10:135-154

White FJ (1991) Social organization, feeding ecology, and reproductive strategy of ruffed lemurs, Varecia variegata. In: Ehara A, Kimura T, Takenaka O, Iwamoto M (eds) Primatology today. Elsevier, Amsterdam New York, pp 81-84 